\title{
Metschnikowiella zobellii sp.nov. and M. krissii sp.nov., two Yeasts from the Pacific Ocean Pathogenic for Daphnia magna
}

\author{
By N. van UDEN aNd R. CASTELO-BRANCO \\ Department of Microbiology, Botanical Institute, University of Lisbon, \\ Lisbon, Portugal
}

(Received 3 March 1961)

\begin{abstract}
SUMMARY
Metschnikowiella zobellii sp.nov. and M. krissii sp.nov. are described and Latin diagnoses given. Both species form on V8 agar (Wickerham, 1951) club-shaped asci containing a single needle-shaped ascospore and are capable of parasitizing Daphnia magna under experimental conditions. $\boldsymbol{M}$. zobellii differs from $\boldsymbol{M}$. krissii by its capacity to ferment glucose and to assimilate galactose, L-sorbose, D-xylose, D-glucosamine, adonitol, D-sorbitol and pyruvate. In infected daphnias the asci and cells of both yeasts resemble Metschnikoff's drawings of $M$. bicuspidata. As cultures of $M$. bicuspidata do not exist and its physiological properties are unknown, the possible identity of either $M$. zobellii or $M$. krissii with $M$. bicuspidata cannot be verified and M. bicuspidata (Metschnikoff 1884) Genkel 1913 is therefore considered a nomen dubium. Both yeasts were repeatedly isolated from marine substrata on and off the coast of La Jolla, California, U.S.A. Minimum numbers of viable organisms in positive samples varied for $M$. zobellii as follows: sea water, $2-58 / 100 \mathrm{ml}$; fish gut contents (of Atherinopis affinis littoralis and Trachurus symmetricus), 25-5,730/ml.; surface of Giant Kelp (Macrocystis pyrifera), 520-39,200/g. M. krissii was isolated only from sea water, $1-57 / 100 \mathrm{ml}$.
\end{abstract}

\section{INTRODUCTION}

Metschnikoff (1884) described as Monospora bicuspidata a yeast-like organism, parasitic in the body cavity of the fresh-water crustacean Daphnia magna. Keilin (1920) summarized Metschnikoff's observations as follows: 'when the cavity of the hosts is entirely invaded by the parasites, these grow in size, become elongated, and form club- or sausage-shaped asci in each of which is developed a single needle-like spore having both ends pointed. When the parasitized host dies, it is filled with ripe spores, and healthy daphnias, which feed on the detritus of their dead and diseased fellows, become infected by ingesting the asci. The latter, when they enter the host's alimentary canal, set free the needle-shaped spores which perforate the gut wall and penetrate in the body cavity, where they germinate laterally, thus starting the new infection'. It was in this material that Metschnikoff made his early observations on the important phenomenon to which he gave the name of phagocytosis.

According to Kudryavtsev (1954), the generic name Monospora was changed by Kamensky (1899) to Metschnikowia because Monospora had been in use, prior to Metschnikoff, for a genus of Algae. Genkel (1913) found out that Metschnikowia had also been in previous use and proposed the name Metschnikowiella. Keilin (1920), 
unaware of this renaming, introduced the name Monosporella and described as Monosporella unicuspidata a second species, observed by him in the body cavity of larvae of the peratogonid fly Dasyhelea obscura. Kudryavtsev (1954) renamed it Metschnikowiella unicuspidata.

Monosporella unicuspidata, as described by Keilin(1920), differs from Monosporella bicuspidata by the morphology of its spores: pointed at one end and truncated at the other in the former species, pointed at both ends in the latter. According to Keilin (1920) a similar yeast was observed by Bütschli in the coelom of a free-living nematode, Tylenchus pellicidus. Mesnil \& Caullery (1911) found yeast-like fungi of elongated shape, in a polychaete worm Potamilla torelli, which they considered related to Monospora, although they did not succeed in finding spores. Also in a pelagic copepod Acartia they observed what they considered to be a similar yeast. None of these yeasts has been cultivated by their authors or by others. Recently one of us isolated from various marine substrata on and off the coast of La Jolla, California, U.S.A., a number of yeasts, which, based on their fermentative and assimilative properties, belong to two distinct species, both morphologically similar with Monosporella bicuspidata. We propose for these two species the names Metschnikowiella zobellii and M. krissii (in honour of Professor Dr C. E. ZoBell and Professor Dr A. E. Kriss, pioneering marine microbiologists, based at La Jolla, California, U.S.A. and Moscow, U.S.S.R., respectively).

\section{METHODS}

Isolation medium. The isolation broth had the following composition $(\%, \mathrm{w} / \mathrm{v})$ : glucose, 2 ; peptone (Difco), 1 ; yeast extract (Difco), 0.5 ; filtered sea water; isolation agar had $2 \%(\mathrm{w} / \mathrm{v})$ agar added. To discourage bacterial growth the medium was adjusted to $\mathrm{pH} 4.5$ with lactic acid.

Isolations from sea water. Subsurface samples were taken at the end of the pier of the Scripps Institution of Oceanography, University of California, La Jolla, California, U.S.A.; $100 \mathrm{ml}$. samples were run through 'Millipore' filters (Millipore Filter Corp.) of the following specifications: HA, pore size $\mathbf{0 . 4 5} \mu$; disk diameter $47 \mathrm{~mm}$; white; plain. Each filter was then placed on top of plated isolation medium.

The plates were incubated at a temperature between $18^{\circ}$ and $20^{\circ}$. After 3-5 days yeast colonies appeared on the filters. These were subcultured to the periphery of the plates. The subcultured colonies were distinguished by macroscopic and microscopic morphology. The numbers of each type were recorded and representatives subcultured to slopes of isolation medium for later identification.

Isolations from fish gut contents. Fish of the species Atherinopis affinis littoralis Ayres ('Topsmelt') and Trachurus symmetricus Ayres ('Pacific Jack Mackerel') were caught with unbaited hooks off the coast of La Jolla, California. The gut contents of each specimen were suspended in twice their volume of filter-sterilized sea-water and $0.2 \mathrm{ml}$. amounts of the suspensions were spread with a glass rod on the surface of isolation medium plates. The plates were incubated at $18^{\circ}-20^{\circ}$, the numbers of yeast colonies recorded according to macroscopic and microscopic morphology. Representative colonies of each type were subcultured for later identification.

Isolations from Giant Kelp. Huge heaps of Giant Kelp (Macrocystis pyrifera) are washed ashore on the beaches of Southern California. Pieces of stems and leaves 
were cut from the subsurface of such heaps, placed in sterile Erlenmeyer flasks and weighed. After the addition of four times the weight of filter-sterilized sea water, the flasks were shaken for $50 \mathrm{~min}$. Serial dilutions of the wash water were then plated on isolation medium and the plates, treated in the same way as the gut-contents plates.

Identification of the yeast isolates. The methods described by Lodder \& Kregervan Rij (1952), Wickerham (1951) and Van Uden \& Farinha (1958), were used. Only isolates belonging to the Metschnikoziella genus are considered in this paper.

Experimental pathogenicity. Yeast-free pond water was placed in $50 \mathrm{ml}$. amounts in wide-mouthed jars together with twenty adult embryo-bearing females of Daphnia magna from a yeast-free laboratory population. Duplicate jars were inoculated with a loopful of growth of a 10-day sporulating culture of either Metschnikowiella zobellii or $M$. krissii; one set was left uninoculated as a control. The jars were incubated at $20^{\circ}$ in a water bath and inspected daily for the presence of dead daphnias. The latter were examined microscopically in unstained preparations and used for making cultures.

\section{RESULTS}

A total of twenty-nine isolates of Metschnikowiella zobellii and six isolates of $M$. krissii were obtained. Their abundance in the various substrata examined can be seen from Table 1. As the possibility of seasonal fluctuations of the Metschnikowiella populations has not been excluded, the dates of collection are given.

Table 1. Minimum numbers of viable cells of Metschnikowiella spp. yeasts in marine substrata

\begin{tabular}{|c|c|c|c|c|c|}
\hline \multirow{3}{*}{$\begin{array}{c}\text { Date of } \\
\text { collection } \\
(1960)\end{array}$} & & & \multicolumn{2}{|c|}{$\begin{array}{l}M . \text { zobellii in } 1 \mathrm{ml} \text {. } \\
\text { fishgut contents of }\end{array}$} & \multirow{3}{*}{$\begin{array}{c}\text { M. zobellii on the } \\
\text { surface of } 1 \mathrm{~g} \text {. } \\
\text { Giant Kelp } \\
\text { (Macrocystis } \\
\text { pyrifera) }\end{array}$} \\
\hline & \multicolumn{2}{|c|}{ In $100 \mathrm{ml}$. seawater } & Atherinopis & & \\
\hline & M. zobellii & M. krissii & littoralis & symmetricus & \\
\hline 12. ii. & 8 & 1 & . & - & 12,600 \\
\hline 19. ii. & 28 & 4 & . & . & 23,000 \\
\hline 21. ii. & 2 & o & . & . & 760 \\
\hline 3. iii. & 2 & $\mathbf{0}$ & . & . & 5,720 \\
\hline 8. iii. & $\overline{0}$ & 14 & 2,100 & 0 & • \\
\hline 11. iii. & 58 & 0 & 275 & . & - \\
\hline 14. iii. & 16 & $\mathbf{0}$ & . & . & - \\
\hline 15. iii. & $\mathbf{0}$ & 25 & $\mathbf{5 2 0}$ & $\mathbf{0}$ & . \\
\hline 23. iii. & 15 & 30 & . & 1,950 & $\mathbf{0}$ \\
\hline 29. iii. & 4 & 0 & . & . & - \\
\hline 30. iii. & 3 & 57 & . & • & $\cdot$ \\
\hline 1. iv. & . & . & . & 5,730 & 39,200 \\
\hline 11. iv. & 42 & $\mathbf{0}$ & $\mathbf{0}$ & 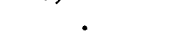 & . \\
\hline 9. v. & 17 & o & 85 & . & . \\
\hline 10. v. & 47 & 0 & 930 & . & 520 \\
\hline 11. v. & 22 & $\mathbf{0}$ & . & 25 & 29,600 \\
\hline 13. v. & 15 & 0 & . & . & o \\
\hline
\end{tabular}




\section{Metschnikowiella zobellii sp.nov.}

In medio liquido cum dextroso et peptono et extracto levedinis cellulae rotundae et ovoideae, $(6-11) \times(7-11) \mu$, singulares, binae aut catenatae; pellicula tenuis formatur. In agaro peptonato cum dextroso et extracto levedinis cultura flavalbida, mollis, subnitida, subreticulata. Pseudomycelium primitivum formatur. Asci in agaro V8 clavati, 18-20 $\mu$; asci in Daphnia magna elongato-subclavati, 30-45 $\mu$. Ascosporae acuiformes, bicuspidatae, ad 1 in asco; in agaro V 8, 15-18 $\mu$, in Daphnia magna, 28-43 $\mu$. Dextrosum fermentatur at non galactosum, saccharum, maltosum, raffinosum, trehalosum et inulinum. Dextrosum, galactosum, L-sorbosum, maltosum, saccharum, cellobiosum, trehalosum, melecitosum, D-xylosum, D-glucosaminum, alcohol aethylicum, glycerinum, adonitolum, D-mannitolum, D-sorbitolum, alpha-methyl-glucosidum, salicinum, arbutinum, acidum pyruvicum et acidum succinicum assimilantur at non nitras kalicus. Necessaria ad fortem crescentiam sunt vitamina externa: biotinum et thiaminum. Temperatura maxima crescentiae $34^{\circ}-35^{\circ}$.

Morphology. In isolation broth after $48 \mathrm{hr}$. at $25^{\circ}$ cells are round and oval, (6-11) $\times(7-11) \mu$, single, in pairs and in small groups. A thin pellicle is formed. The streak culture on isolation agar after 30 days at $25^{\circ}$ is yellowish white, soft, dullglistening and slightly reticulated. A primitive pseudomycelium is formed.

Sporulation. Asci are formed on Henrici's vegetable juice medium (V 8 medium, Wickerham, 1951). No sporulation has been observed to occur on isolation agar, malt agar and corn-meal agar. The asci are club-shaped, 18-21 $\mu$ long and contain a single, needle-shaped ascospore, pointed at both ends and 15-18 $\mu$ long (Fig. 1).

Fermentation, growth in the absence of single vitamins at $25^{\circ}$ and assimilation (see Table 2).

Maximum temperature still permitting growth: $\mathbf{3 4}^{\circ}-\mathbf{3 5}^{\circ}$.

Experimental pathogenicity for Daphnia magna. During the 21 days of observation daphnia populations in the control jars showed no signs of disease and produced a numerous offspring. In the jars inoculated with Metschnikozviella zobellii, dead daphnias began to appear after 3-5 days and the entire population had died after 10-14 days. The dead specimens were densely filled with yeasts; on subculture the dead daphnias produced only $M$. zobellii, no other yeasts. The morphology of $M$. zobellii in the daphnias showed a striking similarity with Metschnikoff's drawings of $M$. bicuspidata, as reproduced by Keilin (1920) and Kudryavtsev (1954). The asci were elongated or slightly clavate, 30-45 $\mu$ long, and contained a single needleshaped ascospore, 28-43 $\mu$ long. The vegetative cells were more slender than the cells on artificial media (Fig. 2).

Type strain. An isolate from sea water has been designated as the type strain of Metschnikowiella zobellii. It is maintained in this laboratory with the number 2892. Subcultures have been deposited with the Yeast Division of the Centraalbureau voor Schimmelcultures, Delft, Netherlands and the Fermentation Division of the Northern Utilization Research and Development Division, Peoria, Illinois, U.S.A.

\section{Metschnikowiella krissii sp.nov.}

In medio liquido cum dextroso et peptono et extracto levedinis cellulae rotundae et ovoideae, $(4 \cdot 5-6) \times(6-11) \mu$ et longovoideae, $(4 \cdot 5-6) \times(11-13) \mu$, singulares, binae 
aut catenatae. In agaro peptonato cum dextroso et extracto levedinis cultura flavalbida, mollis, subnitida, subpunctata. Pseudomycelium primitivum formatur. Asci in agaro V8 clavati, 18-24 $\mu$; asci in Daphnia magna elongato-subclavati vel elongato-angulares, 35-40 $\mu$. Ascosporae acuiformes, bicuspidatae, ad 1 in asco; in agaro V 8, 15-21 $\mu$; in Daphnia magna 32-38 $\mu$. Non fermentat. Dextrosum, maltosum, saccharum, cellobiosum, trehalosum, melecitosum, alcohol aethylicum, glycerinum, D-mannitolum, alpha-methyl-glucosidum, salicinum, arbutinum et acidum succinicum assimilantur, ad non nitras kalicus. Necessaria ad fortem crescentiam sunt vitamina externa: biotinum et thiaminum. Temperatura maxima crescentiae $34-35^{\circ}$.

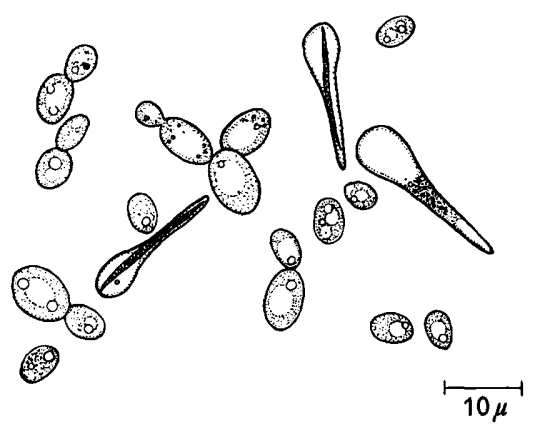

Fig. 1

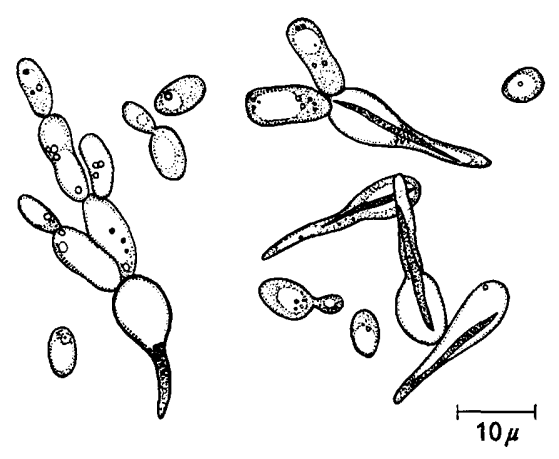

Fig. 3

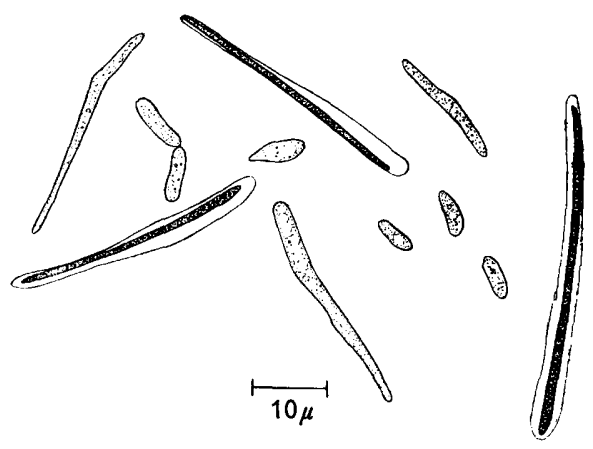

Fig. 2

Fig. 1. Metschnikowiella zobellii. Asci and vegetative cells on V8 medium. Camera lucida drawing.

Fig. 2. Metschnikowiella zobellii. Asci and vegetative cells in parasitized Daphnia magna. Camera lucida drawing.

Fig. 3. Metschnikorviella krissii. Asci and vegetative cells on V8 medium. Camera lucida drawing.

Fig. 4. Metschnikoreiella krissii. Asci and vegetative cells in parasitized Daphnia magna. Camera lucida drawing.

Morphology. In isolation broth after $48 \mathrm{hr}$. at $25^{\circ}$ cells are round and oval, (4.5-6) $\times(6-11) \mu$, and long oval, (4.5-6) $\times(11-13) \mu$, single, in pairs and small groups. A thin pellicle may form after prolonged incubation. The streak culture on 


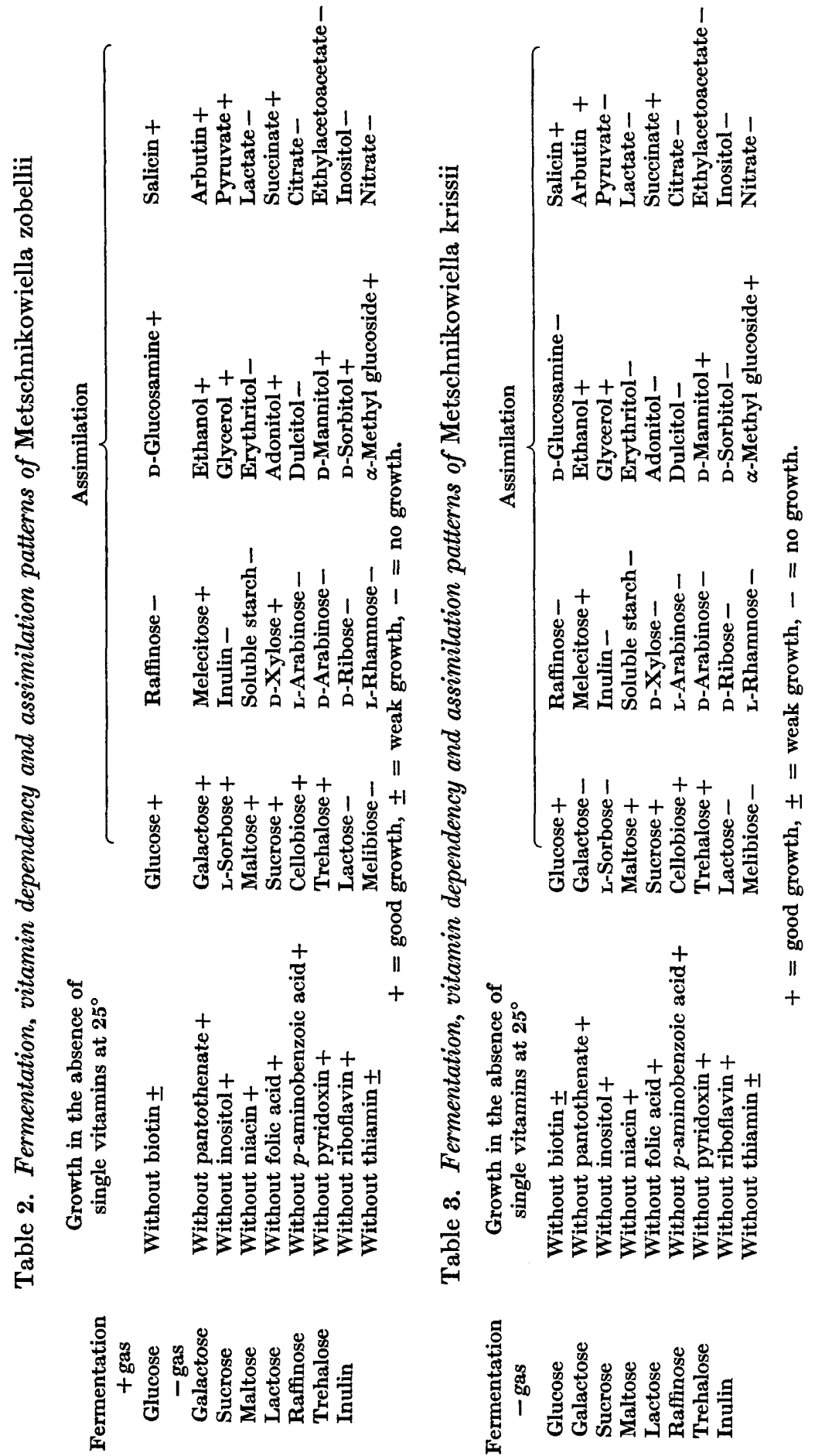


isolation agar after 30 days at $25^{\circ}$ is yellowish white, soft, dull-glistening and slightly pointed. A primitive pseudomycelium is formed.

Sporulation. Asci are formed abundantly on V8 medium (Wickerham, 1951). Sporulation has not been observed on isolation agar, malt agar and corn meal agar. The asci are club-shaped, 18-24 $\mu$ long and contain a single, needle-shaped ascospore, pointed, at both ends and 15-21 $\mu$ long (Fig. 3).

Fermentation, growth in the absence of single vitamins at $25^{\circ}$ and assimilation (see Table 3).

Maximum temperature still permitting growth: $34^{\circ}-35^{\circ}$.

Experimental pathogenicity for Daphnia magna. Metschnikowiella krissii behaved in the same way as M. zobellii. Its morphology in Daphnia magna can be seen in Fig. 4. Many asci were slightly angular.

Type strain. An isolate from sea water has been designated as the type strain of M. krissii. It is maintained in this laboratory with number 2895. Subcultures have been deposited with the Yeast Division of the Centraalbureau voor Schimmelcultures, Delft, Netherlands, and the Fermentation Division of the Northern Utilization Research and Development Division, Peoria, Illinois, U.S.A.

\section{DISCUSSION}

Taxonomy. As Metschnikowiella bicuspidata and M. unicuspidata have not been cultivated in the laboratory, their physiological properties are unknown and no cultures are available for comparative studies. As yeast species identification is largely based on physiological properties, an eventual re-identification of either species would probably imply an arbitrary decision. Their known properties, as described by Metschnikoff and Keilin, are however unique among the yeasts and characterize the genus Metschnikowiella: (1) asci containing a single needle-shaped ascospore; (2) pathogenicity for arthropods. We feel justified therefore to place M. zobellii and M. krissii in Metschnikowiella. An emended description of the genus Metschnikozviella, a discussion of its possible phylogenetic relationships and the designation of a type species is better postponed, we feel, till the life cycles of $M$. zobellii and $M$. krissii have been worked out. Both $M$. zobellii and M. krissii are morphologically similar to $M$. bicuspidata and both are capable, like $\boldsymbol{M}$. bicuspidata, of parasitizing Daphnia magna. As far as Metschnikoff's description of M. bicuspidata goes, our two yeasts would have to be identified with Metschnikoff's organism. This, however, is impossible since $M$. zobellii and $M$. krissii belong to distinct species. $M$. zobellii differs from $M$. krissii by its capacity to ferment glucose and to use galactose, L-sorbose, D-xylose, D-glucosamine, adonitol, D-sorbitol, and pyruvate. This situation exemplifies that Metschnikoff's description of $\boldsymbol{M}$. bicuspidata is not sufficiently complete to allow its re-identification. As, furthermore, no cultures of M. bicuspidata are available to permit an emended description, we have to consider the name Metschnikowiella bicuspidata (Metschnikoff, 1884) Genkel, 1913 as a nomen dubium.

Ecology. Metschnikowiella zobellii and M. krissii were repeatedly isolated from sea water and $M$. zobellii also from Giant Kelp and fish gut (Table 1). This shows that both species, though capable of infecting and killing Daphnia magna, are facultative, rather than obligate parasites. The numbers of viable $M$. zobellii on the surface of Giant Kelp were very high as compared with the numbers found in sea water. In 
most heaps of Giant Kelp from which $M$. zobellii was isolated, slight signs (smell, consistency, temperature) of beginning microbial decomposition were noted. Possibly the breakdown of algal polysaccharides by bacterial action provides certain simple carbohydrates, easily used as a carbon source by $M$. zobellii. The inability of $M$. krissii to assimilate galactose and other carbohydrates may possibly explain why this species was not found in the kelp heaps. The numbers of $\boldsymbol{M}$. zobellii were much higher in fish gut than in sea water. This suggests that $M$. zobellii either multiples in fish gut more actively than in sea water or is associated with some of the marine organisms on which the fish feed. Both $M$. zobellii and $M$. krissii are capable of parasitizing Daphnia magna under experimental conditions. Daphnia magna, however, is a fresh-water crustacean, whereas $M$. zobellii and $M$. krissii seem well adapted to marine environments. Whether these species may, under natural or experimental conditions, parasitize marine crustaceans or other marine animals is an open question.

The isolation work was done during a stay of one author (N.van U.) at the Microbiology Laboratories, Scripps Institution of Oceanography, University of California, La Jolla, California, U.S.A. To Professor Dr C. E. ZoBell and his associates Dr G. E. Jones, Mr H. L. Scotten, Mrs Jean S. ZoBell and Miss Susan Wright warm thanks are expressed for their hospitality and help.

The collaboration of author R. C-B. was made possible by the Direcção Geral dos Serviços Pecuários, Secretariat of Agriculture, Lisbon.

Thanks are due to Mr A. Ferreira of the aquarium 'Vasco da Gama', Lisbon, for Daphnia magna populations and to Dr A. Candeias (University of Lisbon), for checking their identity. This work was supported by the Calouste Gulbenkian Foundation, Lisbon.

\section{REFERENCES}

Genkel, A. (1913). Essay on Sporulating Plants. Moscow: Knebel.

KAMENSKy, F. M. (1899). On a new view of the genus Metschnikorwia (Monospora Metsehnikoff). Treat. spb. soc. natural. (Russian), 30, part 5.

KeILIN, D. (1920). On a new saccharomycete Monosporella unicuspidata gen. n.nom., n.sp., parasitic in the body cavity of a dipterous larva (Dasyhelea obscura (Winnertz). Parasitology, 12, 83.

Kudryavtsev, V. I. (1954). Systematics of the Yeasts. Moscow: Ysdatelstwo Akademyi Nauk SSSR.

Lodder, J. \& Kreger-van RiJ, N. J. W. (1952). The Yeasts. Amsterdam: North Holland Publishing Company.

Mesnil, F. \& Caullery, M. (1911). Neoformations papillomateuses chez une Annélide (Potamilla torellii) dues probablement à l'influence de parasite (Haplosporidie et levure). Bull. Sci. Fr. Belg. 45, 89.

Metschnikoff, E. (1884). Ǔber eine Sprosspilzkrankheit der Daphnien. Beitrag zur Lehre über den Kampf der Phagocyten gegen Krankheitserreger. Virchowes Arch. 96, 177.

van Uden, N. \& Farinha, M. (1958). On the significance of temperature relations and vitamin deficiency patterns in the delimitation of yeast species. Port. Acta biol. (B), 6, 161.

Wickerham, L. J. (1951). Taxonomy of Yeasts. Tech. Bull. U.S. Dep. Agric. no. 1029. 